\title{
Sterilization by gas ovens
}

\author{
E. A. K. PATRICK, R. H. WhARTON, K. PRENTIS, ANd A. G. SigNy \\ From North Thames Gas Board and St. Mary Abbots Hospital, London
}

SYNOPSIS A forced convection gas-fired oven has been designed which will sterilize a very heavy load of syringes and instruments and containers. It is superior to a gas-fired, infrared, radiant-heated oven which was designed for sterilizing syringes.

Developments in the techniques of hot-air sterilization have been mainly directed to improvements in the conventional hot-air ovens themselves in order to ensure an even distribution of heat in the oven (Darmady and Brock, 1954). The incorporation of a fan has to a large extent overcome the uneven distribution of heat leaving pockets of cooler air which had led to failures in sterilization. Later, the introduction of the tunnel type of heater, using infra-red panel heating and a conveyor belt, speeded up the whole process, ensured a quick warming up of the materials to be sterilized, and, using a standard load, gave very reliable results (Darmady, Hughes, and Tuke, 1957). The heavy electrical load and the need for voltage stabilizers are disadvantages in many cases, and itwas thought that town gas as an alternative source of heating, and, to save space, a vertical form of oven, should be tried.

This paper therefore deals with two experimental installations: the first comprises a radiant heating unit with a vertically moving conveyor, and the second a forced convection unit with a horizontal conveyor. It should be pointed out that these are only two of the possible combinations of heating methods and conveyor disposition possible, since there is no reason why gas-fired radiant heating cannot be applied to a horizontal conveyor or forced convection to the vertical unit. Therefore the discussion of the results which follows later in the paper deals with these two aspects separately.

\section{RADIANT HEATING UNIT}

This unit is based upon a proprietary radiant heating panel, of which seven are used, each with a radiant surface 12 in. $\times 24$ in. The syringes are carried vertically upward in front of four of the panels and pass downwards over the other three, being carried singly in special baskets on a chain-link conveyor. The syringes, assembled in the standard pattern
Nuffield aluminium containers, are placed on an in- $N$ clined plane-feed hopper from which they are auto- 을 matically taken up into one of the basket carriers on the conveyor and are eventually discharged, after sterilizing, on the other side of the machine.

The overall dimensions are $2 \mathrm{ft} .4$ in. $\times 2 \mathrm{ft} .9$ in. $\times 7 \mathrm{ft} .6 \mathrm{in}$. high (Fig. 1). In order to use the full width of the proprietary radiant panel a double con- $\mathscr{8}$ veyor was installed, which will carry 150 syringes an hour. The unit is thermostatically controlled and for the experimental period has been fitted with a variable speed drive. Eventually it was decided that the best results were achieved with a conveyor speed which completed the heating cycle of a given syringe $\stackrel{\square}{\unrhd}$ in $\mathbf{3 0}$ minutes.

\section{FORCED CONVECTION UNIT}

This unit was built around an existing conveyor $2 \mathrm{ft} .3 \mathrm{in}$. wide and comprises an oven space extending 8 in. above the conveyor some $8 \mathrm{ft}$. long (Fig. 2). The oven is constructed from Marinite insulating board supported by an angle iron frame, and the sides 3 are extended $15 \mathrm{in}$. above the working space to in- 0 corporate the feed and return air ducts and the air heater and fan, thus giving a compact unit. The airo heater has a No. 200 Hypact burner and is provided with a thermoelectric flame failure device and a fan $N$ failure switch, and is subject to thermostatic control. N A $\frac{1}{2}$ h.p. single-phase motor drives a centrifugal fan N which provides forced recirculation of the hot gases ${ }_{\sigma}^{\omega}$ through the working space in concurrent flow with the conveyor belt. A variable-speed motor drives the conveyor and can give heating times from a rapid five minutes up to 130 minutes.

As in the case of the radiant heating unit, this oven ${ }_{0}^{\circ}$ is also a prototype and was constructed to prove the $\vec{\Phi}$ operating characteristics. The horizontal conveyor $\frac{\mathbb{P}}{\mathbb{D}}$ has the advantage that objects of any size or shape $\varrho$ can be placed upon it, and the oven height has been? 


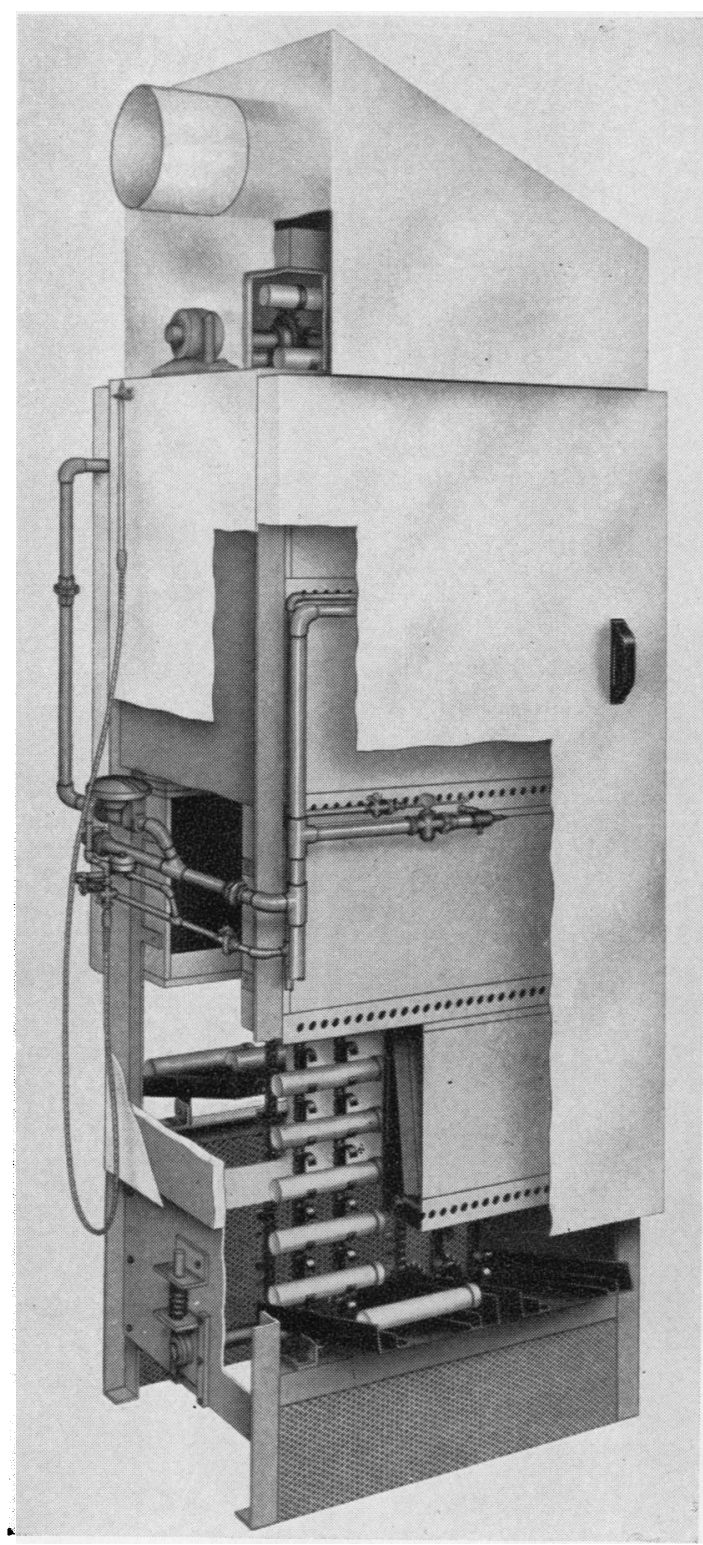

FIG. 1. Vertical radiant sterilizer for hypodermic syringes.

chosen to permit sterilizing of all the usual variety of containers, not only syringes but instruments, bowls, etc. It would be a simple matter to arrange for all sterilized objects to be automatically conveyed away.

\section{TEST PROCEDURES}

Copper-constantan thermocouples were buried in the plungers of syringes which were then assembled in the ordinary way. All sizes of syringes were tested in different ways but special attention was paid to the $2 \mathrm{ml}$. and the $20 \mathrm{ml}$. syringes as being the most widely different in size of those in general use. The experiments of Darmady et al. (1957) on the effect of new and old containers, blackening of containers, etc., were repeated and in the main confirmed with the radiant heating panels. Bacteriological testing was done using samples of earth, spores of $B$. subtilis, and spores of $B$. stereothermophilus. The spores were dried on blotting paper discs which were inserted into the base of the barrel of the syringe. The syringes were then fitted with a plunger and packed in the usual way. All tests were carried out at the beginning, the middle, and the end of a sterilizing run.

\section{RESULTS}

Figs. 3-7 are time temperature curves obtained with the thermocouples as described. Figs. 3 and 4 refer to the radiant heated oven, and Figs. 5, 6, and 7 to the convection oven. The first two graphs show that the

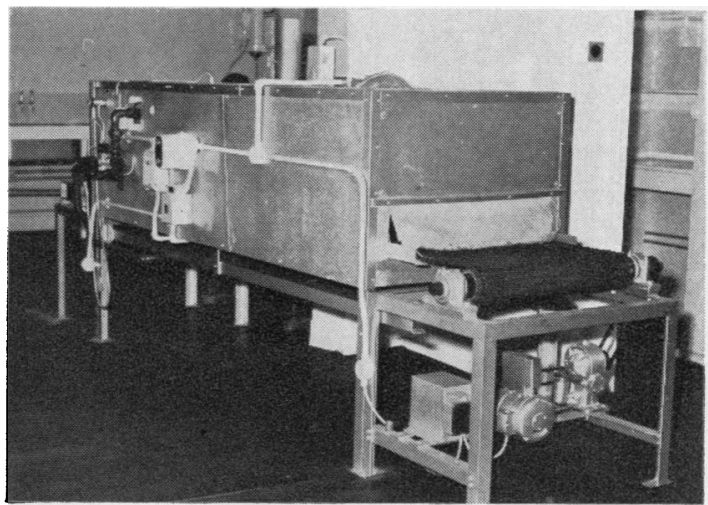

FIG. 2. Forced convection unit.

syringes receive radiation from the first panel within a few minutes and reach the required temperature of $160^{\circ} \mathrm{C}$. or $180^{\circ} \mathrm{C}$. within 10 minutes. The speed of the conveyor can be adjusted to allow for a slower warming up period but a much longer time at sterilizing temperature. The aim has been, however, to achieve a cycle of about half-an-hour, with a period of 15 minutes at $180^{\circ} \mathrm{C}$. It will be seen from Fig. 4 that although this is achieved with old containers, new highly polished aluminium containers prevented the quick absorption of heat, resulting in a very short period at sterilizing temperatures. Fig. 3 shows that although the rate of heat uptake is somewhat different in different sizes of syringes the time of sterilizing temperatures is adequate without alteration of the controls. 


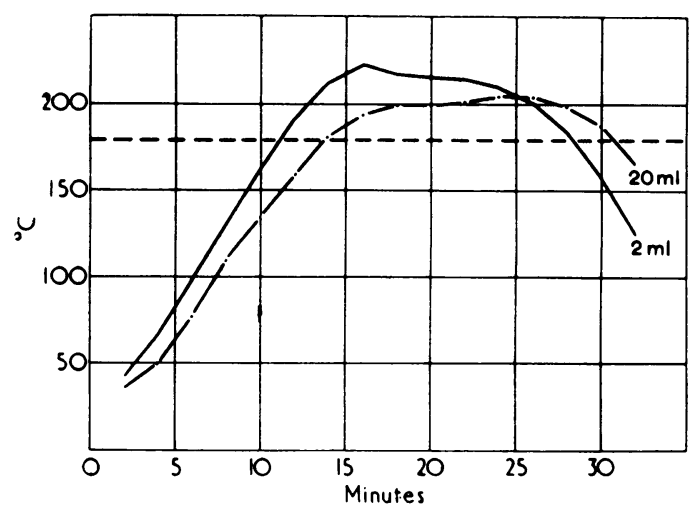

FIC. 3. Results of tests using the radiant heating oven for syringes of different sizes maintained at a constant oven temperature.

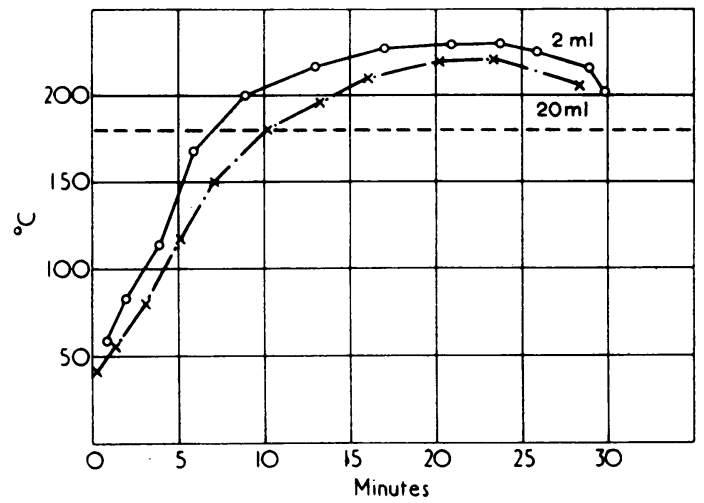

FIG. 5. Results of tests using the convection oven for syringes of different sizes maintained at a constant temperature.

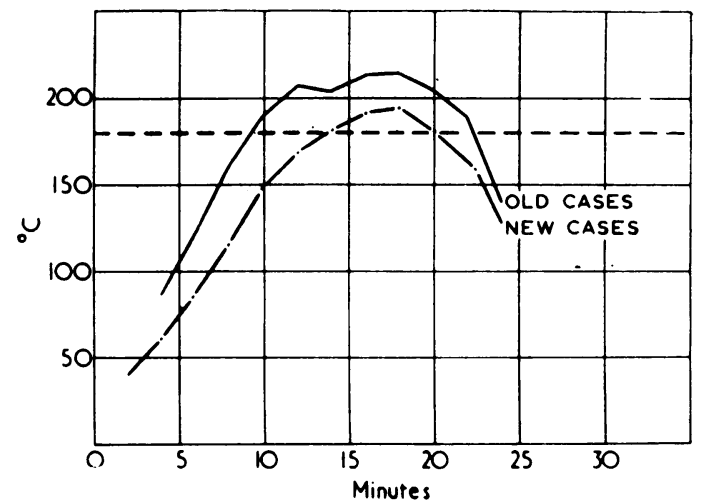

FIG. 4. Results of tests using the radiant heating oven for syringes of identical size in old and new cases.

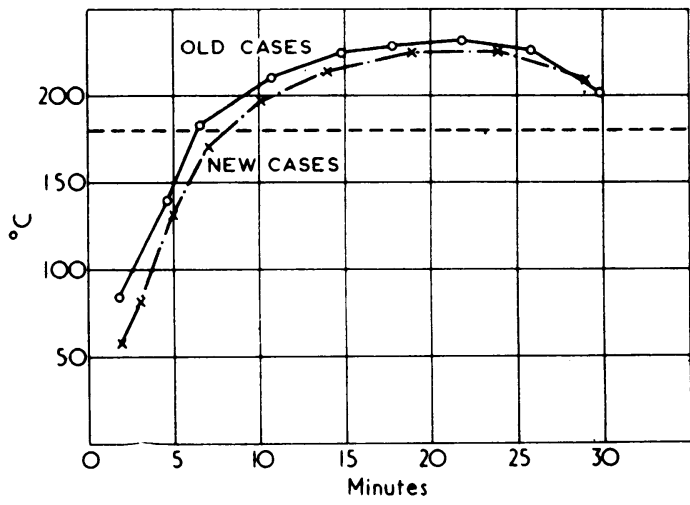

FIG. 6. Results of tests using the convection oven for syringes of identical size in old and new cases.

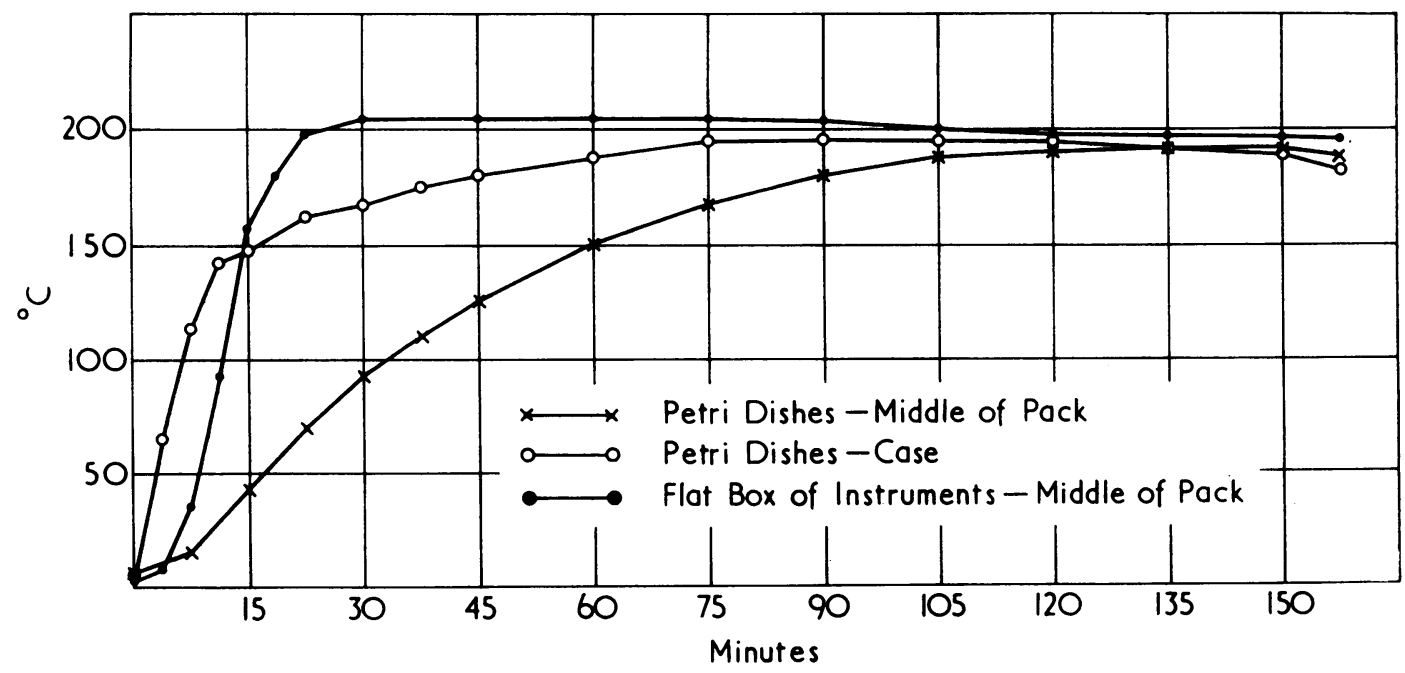

FIG. 7. Results of tests using the convection oven for other articles. 


\section{T A B LE}

Maximum throughput

Ignition

Warming-up time of oven

Heating-up time of syringes

Effect of differing sizes of syringe

Effect of surface condition of goods

Control of maximum temperature

Control of heat input

Fuel consumption per hour at maximum loading

Fuel consumption per 1,000 syringes

B. Comparison of Conveyor Systems

Type of load

\section{0 syringes per hour}

At seven points

80 minutes

12-14 minutes

This can be seen by comparing Figs. 3 and 5 . In both cases the small syringe has a peak temperature some $20^{\circ} \mathrm{C}$. higher than the large syringe. The convection oven shows a greater retardation of heating-up for large syringes

Fig. 4 shows that new tubes, being highly polished, are poor absorbers and this affects both heating time and final temperatures

Each heating panel has to be individually set to give the required heating cycle

Control of heating source is indirect, depending on heating by radiation of thermostat in a central, representative position

$1 \cdot 15$ therms

0.64 therms

$7 \cdot 7$ therms

Purpose-built conveyor will take only syringes

Small, at expense of added height
$1 \cdot 3$ therms

Fig. 6 shows that, with convection heating, there is little difference between old and new tubes

Maximum hot air temperature cannot be

Control of heating medium direct by thermostat in hot air feed to oven

Any object less than 6 in. high can be sterilized, e.g., instruments, bowls, etc. Adjustment of conveyor speed only is required

Relatively large, but height not great exceeded. Temperatures steady
Figs. 5 and 6 show the same tests carried out on the forced convection heater, and here it can be seen that there was essentially no difference in the results whether large or small syringes were tested or whether new or old containers were used. Fig. 7 relates to larger objects with thermocouples at the positions indicated.

Bacteriologically the results were eminently satisfactory in both types of oven. No growth was ever obtained with a syringe which had been exposed to at least $180^{\circ} \mathrm{C}$. for 10 minutes. It is important to check control spore papers, as there is occasionally deterioration and a false sense of security may be felt when spores are too readily killed on heating.

\section{DISCUSSION}

The advantages of the forced convection oven over the infrared radiant heating oven are clearly shown in the table of comparisons. The most important seem to be that the temperature of the second half of the convection oven is very constant, and that objects of varying shapes and sizes reach and maintain this temperature. Because the temperature is maintained by a forced circulation, and due to a sensitive temperature control, there is very little difference in the eventual temperature and time of exposure between new and old containers when they are mixed in one load, or between syringes and containers of very different sizes. This makes for greater ease and flexibility in working. The radiant-heated vertical oven, although it gave very good results, was very much more limited and could only be used for syringes, and preferably syringes of similar size and the same type of container. The running cost of the forced convector oven per syringe was approximately one-sixth that of the infrared panel heater.

Our thanks are due to the Nuffield Foundation and the South West Metropolitan Regional Board, which gave grants to cover some of the expenses, and to the North Thames Gas Board. We should also like to thank Mr. Whiter and Mr. Addiscot, of the Engineering Department of St. Mary Abbot's Hospital, for their help.

\section{REFERENCES}

Darmady, E. M., and Brock, R. Barrington (1954). J. clin. Path., 7, 290.

_-, Hughes, K. E. A. and Tuke, W. (1957). Ibid., 10, 291. 